\title{
Excess X-ray Scattering Observed at Low Angles during Melting of Crystalline-Amorphous Diblock Copolymers
}

\author{
By Keiko TonamI ${ }^{1}$ Shuichi NoJIMA, ${ }^{1, *}$ Takashi Honda, ${ }^{2}$ and Yasuo TSUNOGAE ${ }^{2}$
}

The heating process of a series of new crystalline-amorphous diblock copolymers, hydrogenated polynorbornene-blockhydrogenated poly(1,4-methano-1,4,4a,9a-tetrahydrofluorene) (hPNB- $b$-hPMTF), has been investigated using time-resolved small-angle X-ray scattering with synchrotron radiation. When the crystalline hPNB block was the major component in hPNB- $b$-hPMTF, the crystallization temperature of hPNB blocks at the maximum rate $T_{\mathrm{c}}{ }^{*}$ (i.e., the peak temperature of DSC exotherms during cooling at $-5^{\circ} \mathrm{C} / \mathrm{min}$ ) was found to be nearly the same to the glass transition temperature $T_{\mathrm{g}}$ of amorphous hPMTF blocks. For these copolymers, the excess upturn scattering at low angles was transiently observed during the melting of hPNB blocks, which depended significantly on the composition and the thermal history applied to hPNB- $b$-hPMTF before heating. The crystallized lamellar morphology (i.e., an alternating structure consisting of hPNB lamellar crystals and amorphous hPNB + hPMTF layers), which had been gradually transformed from the molten microdomain structure by the crystallization of hPNB blocks, was responsible for the emergence of this scattering, because the excess X-ray intensity was proportional to the volume fraction of the crystallized lamellar morphology existing in the system. We discussed the possible origin of this excess scattering by considering the morphological change during melting.

KEY WORDS: Crystalline-Amorphous Diblock Copolymer / Melting Process / Synchrotron SAXS / Excess X-ray Scattering /

The morphology formation of crystalline-amorphous diblock copolymers is complicated depending on the relative position of the order-disorder transition temperature of block copolymers $T_{\mathrm{ODT}}$, the crystallization temperature $T_{\mathrm{c}}$ of crystalline blocks, and the glass transition temperature $T_{\mathrm{g}}$ of amorphous blocks. ${ }^{1-3}$ When $T_{\mathrm{ODT}}>T_{\mathrm{g}}>T_{\mathrm{c}}$, the molten microdomain structure is frozen at $T_{\mathrm{c}}$ and eventually crystallization is effectively confined within this structure (confined crystallization), resulting in a crystallized microdomain structure. ${ }^{4-14}$ When $T_{\mathrm{ODT}}>T_{\mathrm{c}}>T_{\mathrm{g}}$, on the other hand, the microdomain structure is completely replaced with a crystallized lamellar morphology, an alternating structure consisting of lamellar crystals and amorphous layers, if the total molecular weight and the interaction between two blocks are not large enough (break-out crystallization). ${ }^{15-24}$ However, there are limited studies on the morphology formation of crystalline-amorphous diblocks with $T_{\mathrm{ODT}}>T_{\mathrm{g}} \sim T_{\mathrm{c}}{ }^{25-27} \mathrm{Ho}$ et al., for example, investigated the morphology of synpolypropylene-block-polystyrene $\left(s \mathrm{PP}-b\right.$-PS) ${ }^{27}$ where $T_{\mathrm{g}}$ of amorphous PS blocks partially overlapped with the $T_{\mathrm{c}}$ range of crystalline $s$ PP blocks. They observed confined or break-out crystallization according to $T_{\mathrm{c}}$ they used. Thus, we can expect that the crystallization behavior and resulting morphology of crystalline-amorphous diblocks with $T_{\mathrm{g}} \sim T_{\mathrm{c}}$ depend significantly on $T_{\mathrm{c}}$ and also the crystallization time $t_{\mathrm{c}}$, because the mobility of polymer chains is extremely reduced during crystallization. As a result, the melting behavior of such copolymers will be also influenced by the crystallization condition.
In this manuscript, we try to understand the morphology formation of crystalline-amorphous diblocks with $T_{\mathrm{c}} \sim T_{\mathrm{g}}$ by investigating their melting behavior mainly using synchrotron small-angle X-ray scattering (SR-SAXS). The block copolymers we used are hydrogenated polynorbornene-blockhydrogenated poly(1,4-methano-1,4,4a,9a-tetrahydrofluorene) (hPNB- $b$-hPMTF, Scheme 1) with various compositions, in which both the blocks have been intentionally chosen to meet the condition of $T_{\mathrm{g}} \sim T_{\mathrm{c}}$. When the hPNB block is rich in hPNB- $b$-hPMTF, the crystallization temperature of hPNB blocks at the maximum rate $T_{\mathrm{c}}{ }^{*}$ (i.e., the peak temperature of DSC exotherms during cooling at $-5^{\circ} \mathrm{C} / \mathrm{min}$ ) is $c a .115^{\circ} \mathrm{C}$ and $T_{\mathrm{g}}$ of hPMTF blocks is $c a .122^{\circ} \mathrm{C}$ (Figure 2). Therefore, when hPNB- $b$-hPMTF is crystallized at $T_{\mathrm{c}}{ }^{*}{ }^{28}$ the molecular motion is expected to be considerably restricted by the glass transition of hPMTF blocks, which will result in a variety of morphologies depending on the crystallization time $t_{\mathrm{c}}$. Actually, when the crystallized hPNB- $b$-hPMTF was heated at a constant rate, we observed an interesting melting behavior. That is, we had an excess upturn scattering at low angles transiently appearing in the melting temperature range of $\mathrm{hPNB}$ blocks (Figure 3), which depended significantly on the composition and $t_{\mathrm{c}}$. The aim of this study is to clarify the detailed conditions to observe this excess scattering at low angles, and furthermore to understand the complicated morphology formation at $T_{\mathrm{c}}{ }^{*}$ in order to explain the characteristic melting behavior observed in our block copolymers.

The excess upturn $\mathrm{X}$-ray scattering at low angles was sometimes reported during the melting process of crystalline

\footnotetext{
${ }^{1}$ Department of Organic and Polymeric Materials, Graduate School of Science and Engineering, Tokyo Institute of Technology, H-125, 2-12-1 Ookayama, Meguro-Ku, Tokyo 152-8552, Japan

${ }^{2}$ Zeon Corporation, 1-2-1 Yako, Kawasaki-ku, Kawasaki, 210-9507, Japan

*To whom correspondence should be addressed (Tel: +81-3-5734-2132, Fax: +81-3-5734-2888, E-mail: snojima@ polymer.titech.ac.jp).
} 


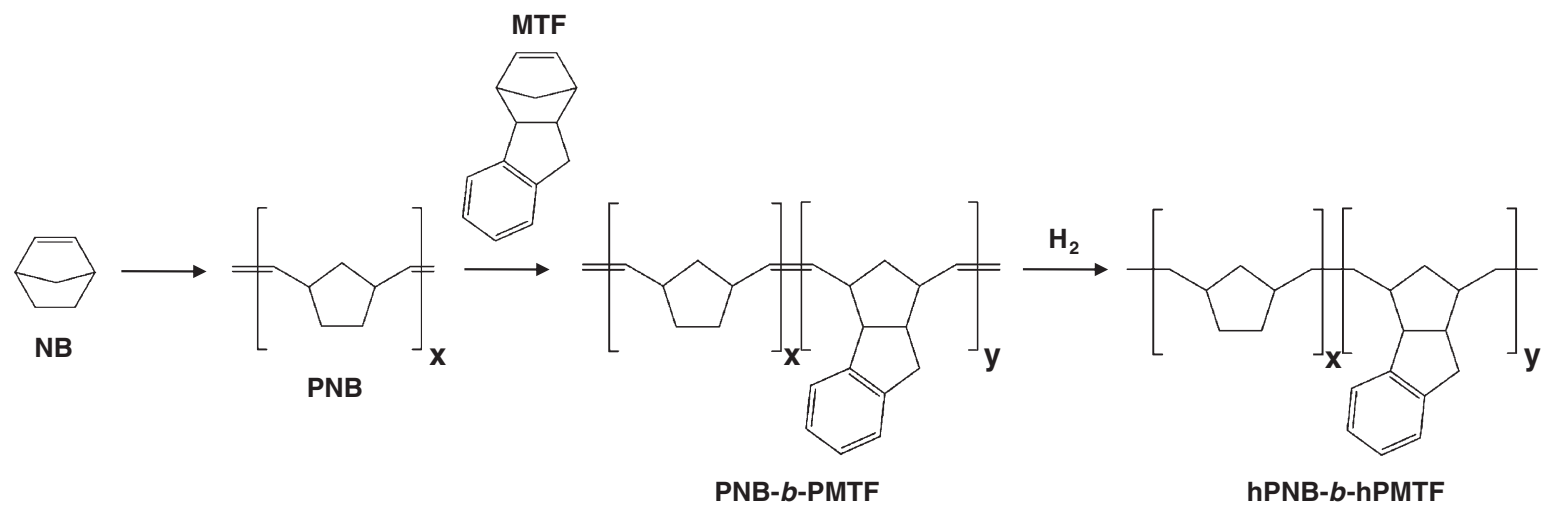

Scheme 1 .

homopolymers, ${ }^{29-31}$ which has been believed to arise from the heterogeneous distribution of electron density when the crystallized lamellar morphology was melting during heating. However, the substantial origin of this excess scattering is not clarified mainly because of the transient process observed only with the time-resolved SR-SAXS technique. We think that the emergence of the scattering might be a clue to understand the complicated morphology formation by a combined effect of crystallization and glass transition in crystalline-amorphous diblocks with $T_{\mathrm{g}} \sim T_{\mathrm{c}}$.

\section{EXPERIMENTAL}

\section{Samples}

The crystalline-amorphous diblock copolymers used in this study are a serious of hydrogenated polynorbornene-blockhydrogenated poly(1,4-methano-1,4,4a,9a-tetrahydrofluorene) (hPNB- $b$-hPMTF, hPNB is crystalline and hPMTF amorphous) copolymers with various compositions. The synthesis route is briefly shown in Scheme 1. The norbornene monomer (NB) in toluene was first polymerized at room temperature for $c a .1 \mathrm{~h}$ with Grubbs catalyst (bis(tricyclohexylphosphine) benzylidine ruthenium(IV) chloride) as an initiator, followed by the addition of 1,4-methano-1,4,4a,9a-tetrahydrofluorene monomer (MTF) to synthesize PNB- $b$-PMTF at room temperature for $c a$. $5 \mathrm{~d}$. The NB/initiator and NB/MTF ratios were adjusted to obtain PNB- $b$-PMTF with various compositions and molecular weights. Next, PNB- $b$-PMTF in xylene was hydrogenated with $p$-toluenesulfonyl hydradide at $120^{\circ} \mathrm{C}$ for $8 \mathrm{~h}$ to obtain hPNB$b$-hPMTF. All the samples synthesized were characterized using gel permeation chromatography with polystyrene standards, and the composition was evaluated by ${ }^{1} \mathrm{H}$ NMR.

Table I shows the molecular characteristics of the samples used in this study, where the numerals in the sample code represent wt. $\%$ of hPNB blocks in hPNB- $b$-hPMTF. The total molecular weight of hPNB- $b$-hPMTF is in a range between 21,000 and 46,000, and the composition changes from 12 to 79 wt. $\%$ hPNB. These copolymers will be weakly microphaseseparated in the melt judging from the fact that we observed a
Table I. Samples used in this study

\begin{tabular}{lcccccc}
\hline \multirow{2}{*}{ Sample Code } & $M_{\mathrm{n}}{ }^{\mathrm{a}}$ & $M_{\mathrm{w}} / M_{\mathrm{n}}{ }^{\mathrm{a}}$ & $\mathrm{hPNB}: \mathrm{hPMTF}$ & $T_{\mathrm{c}}^{* \mathrm{c}}$ & $T_{\mathrm{m}}{ }^{\mathrm{d}}$ & $T_{\mathrm{g}}{ }^{\mathrm{d}}$ \\
\cline { 2 - 7 } & $(\mathrm{g} / \mathrm{mol})$ & & $(\mathrm{wt} . \%)$ & $\left({ }^{\circ} \mathrm{C}\right)$ & $\left({ }^{\circ} \mathrm{C}\right)$ & $\left({ }^{\circ} \mathrm{C}\right)$ \\
\hline B12 & 21,000 & 1.26 & $12: 88$ & 50 & 111 & 121 \\
B18 & 28,000 & 1.23 & $18: 82$ & 56 & 110 & 119 \\
B25 & 25,000 & 1.29 & $25: 75$ & 57 & 103 & 123 \\
B33 & 25,000 & 1.25 & $33: 67$ & 66 & 116 & 124 \\
B49 & 23,000 & 1.12 & $49: 51$ & 74 & 127 & - \\
B61 & 46,000 & 1.20 & $61: 39$ & 108 & 131 & - \\
B68 & 31,000 & 1.13 & $68: 32$ & 109 & 135 & - \\
B79 & 44,000 & 1.09 & $79: 21$ & 123 & 144 & - \\
& & & & & & \\
hPNB & 9,100 & 2.18 & $100: 0$ & 117 & 136 & - \\
hPMTF & 15,000 & 2.02 & $0: 100$ & - & - & 141 \\
\hline
\end{tabular}

a Determined by GPC with polystyrene standards. ${ }^{b}$ Determined by ${ }^{1} \mathrm{H}$ NMR. ${ }^{\mathrm{c}}$ Determined by $\mathrm{DSC}$ with a cooling rate of $-5^{\circ} \mathrm{C} / \mathrm{min}$. dDetermined by DSC with a heating rate of $5^{\circ} \mathrm{C} / \mathrm{min}$.

morphological transition (molten microdomain structure $\rightarrow$ crystallized lamellar morphology) by a static SAXS method when B61, B68, and B79 (with $T_{\mathrm{g}} \sim T_{\mathrm{c}}{ }^{*}$ ) were annealed at $T_{\mathrm{c}}{ }^{*}$ for a long time $(\geq 4 \mathrm{~h}){ }^{32}$ For comparison purpose, the corresponding homopolymers, hPNB and hPMTF, were also synthesized using the method described above.

\section{Thermal History Applied to the Samples}

We employed two thermal histories (Figure 1) to crystallize hPNB blocks, and subsequently the melting behavior was observed by differential scanning calorimetry (DSC) and independently by time-resolved SR-SAXS. In the first thermal history (Figure 1a), the molten sample at $150^{\circ} \mathrm{C}$ was cooled into room temperature at a constant rate of $-5^{\circ} \mathrm{C} / \mathrm{min}$, during which the hPNB block crystallized, and then the sample was heated at a rate of $5^{\circ} \mathrm{C} / \mathrm{min}$ to observe the melting behavior. In the second thermal history (Figure 1b), the molten sample at $150{ }^{\circ} \mathrm{C}$ was quenched into $T_{\mathrm{c}}{ }^{*}$ (shown in Table I), crystallized there for a prescribed crystallization time $t_{\mathrm{c}}$ ranging from $0 \mathrm{~h}$ (corresponding to no crystallization at $T_{\mathrm{c}}{ }^{*}$ ) to $14 \mathrm{~h}$, and then quenched into room temperature. The sample was finally heated at a rate of $5^{\circ} \mathrm{C} / \mathrm{min}$ to observe the melting behavior. 

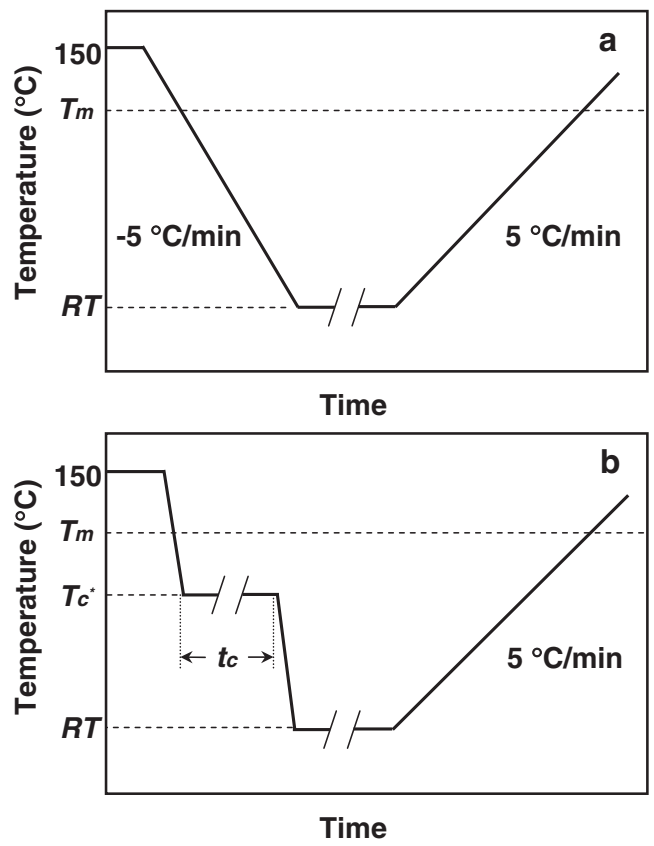

Figure 1. Thermal histories applied to the samples to observe the melting behavior using SR-SAXS and DSC. (a) The microphase-separated sample at $150^{\circ} \mathrm{C}$ was cooled at $-5^{\circ} \mathrm{C} / \mathrm{min}$ to room temperature, kept there for a long time, and then heated at $5^{\circ} \mathrm{C} /$ min until hPNB blocks melted completely. (b) The microphase-separated sample at $150^{\circ} \mathrm{C}$ was first quenched into $T_{\mathrm{c}}{ }^{*}$ (shown in Table I), annealed at $T_{\mathrm{c}}{ }^{*}$ for a prescribed time $t_{\mathrm{c}}$ $\left(0 \leq t_{c} \leq 14 \mathrm{~h}\right)$ to crystallize hPNB blocks, quenched again into room temperature, and finally heated at $5^{\circ} \mathrm{C} / \mathrm{min}$ until hPNB blocks melted completely.

\section{SR-SAXS Measurements}

The time-resolved SR-SAXS measurements during heating were performed at Photon Factory in High Energy Accelerator Research Organization, Tsukuba Japan, with a small-angle $\mathrm{X}$-ray equipment for solution (SAXES) installed at beam line BL-10C. Details of the equipment and the instrumentation are described elsewhere. ${ }^{33-36}$ The scattered intensity during heating was recorded with a one-dimensional position-sensitive proportional counter with the accumulation time of $10 \mathrm{~s}$. The SRSAXS curves measured were corrected for the background scattering and the absorption by the samples, but not for the smearing effect because SAXES employed a point-focusing optics. The SAXS curves were finally obtained as a function of wave number $s$ defined as $s=(2 / \lambda) \sin \theta$, where $2 \theta$ is the scattering angle and $\lambda$ is the $\mathrm{X}$-ray wavelength used $(=0.1488 \mathrm{~nm})$. The static SAXS measurements for crystallized hPNB- $b$-hPMTF (Figure 6) were also performed at room temperature using SAXES.

\section{DSC Measurements}

A Perkin Elmer DSC Pyris 1 was used to evaluate $T_{\mathrm{g}}$ of the hPMTF block and $T_{\mathrm{c}}{ }^{*}$ and $T_{\mathrm{m}}$ of the hPNB block. $T_{\mathrm{c}}{ }^{*}$ was determined from the exothermic peak temperature in the DSC curve when the sample was cooled at $-5^{\circ} \mathrm{C} / \mathrm{min}$ from the melt. $T_{\mathrm{m}}$ and $T_{\mathrm{g}}$ were determined during heating the samples at $5{ }^{\circ} \mathrm{C} / \mathrm{min},{ }^{37}$ which were in advance cooled down at $-5^{\circ} \mathrm{C} / \mathrm{min}$ from the melt into room temperature (Figure 1a).

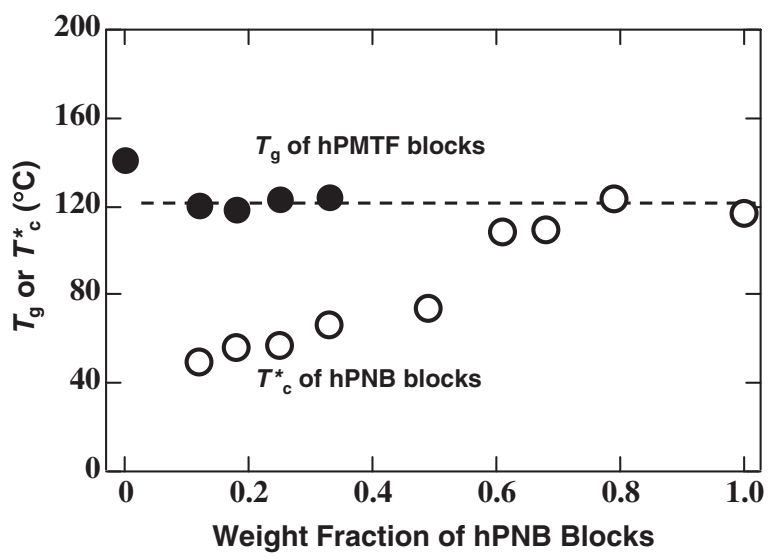

Figure 2. $T_{\mathrm{g}}$ of hPMTF blocks and $T_{\mathrm{c}}{ }^{*}$ of $\mathrm{hPNB}$ blocks plotted against the weight fraction of hPNB blocks in the system. $T_{\mathrm{g}}$ was obtained using DSC during heating at $5^{\circ} \mathrm{C} / \mathrm{min}$ from room temperature and $T_{\mathrm{C}}{ }^{*}$ during cooling at $-5^{\circ} \mathrm{C} / \mathrm{min}$ from $150^{\circ} \mathrm{C}$.

For hPNB- $b$-hPMTF containing hPNB blocks as the minor component (i.e., B12 B33), the melting endothermic peak was small and $T_{\mathrm{m}}$ was significantly lower than $T_{\mathrm{g}}$, and therefore we could evaluate $T_{\mathrm{m}}$ and $T_{\mathrm{g}}$ separately. For other hPNB- $b$ hPMTF (B49 B79), on the other hand, the melting peak was large and its tail was overlapped with the glass transition range of hPMTF blocks, so that $T_{\mathrm{g}}$ could not be successfully evaluated.

\section{RESULTS}

\section{Thermal Characterization of hPNB- $b$-hPMTF}

First of all, we evaluated $T_{\mathrm{g}}$ of hPMTF blocks using DSC during heating and $T_{\mathrm{c}}{ }^{*}$ of hPNB blocks during cooling. Figure 2 shows the plot of $T_{\mathrm{g}}$ and $T_{\mathrm{c}}{ }^{*}$ against the weight fraction of hPNB blocks in the system $\phi_{\mathrm{hPNB}}$. $T_{\mathrm{g}}$ for $\mathrm{B} 12 \sim \mathrm{B} 33$ is almost constant $\left(\sim 122^{\circ} \mathrm{C}\right)$, and slightly lower than that of the hPMTF homopolymer $\left(\sim 141^{\circ} \mathrm{C}\right)$. On the other hand, $T_{\mathrm{g}}$ for $\mathrm{B} 49 \sim \mathrm{B} 79$ could not be evaluated because the glass transition range of hPMTF blocks was overlapped with the tail of hPNB melting endotherms. The DSC and SR-SAXS results described below show that $\mathrm{B} 12 \sim \mathrm{B} 33$ form the crystallized microdomain structure owing to confined crystallization. Therefore, $T_{\mathrm{g}}$ arises from neat hPMTF microdomains and hence remains constant irrespective of $\phi_{\mathrm{hPNB}} . \mathrm{B} 49 \sim \mathrm{B} 79$ also have neat hPMTF regions at room temperature, i.e., hPMTF microdomains, hPMTF layers in the crystallized lamellar morphology, or both, depending on the composition and the crystallization condition, as described later. Therefore, $T_{\mathrm{g}}$ for B49 $\sim \mathrm{B} 79$, which will arise from these neat hPMTF regions, is expected to be nearly the same to that for B12 B33, as shown by the extrapolated broken line in Figure 2.

Figure 2 also shows that $T_{\mathrm{c}}{ }^{*}$ depends significantly on $\phi_{\mathrm{hPNB}}$. That is, $T_{\mathrm{c}}{ }^{*}$ is less than $80^{\circ} \mathrm{C}\left(\ll T_{\mathrm{g}}\right)$ for $\mathrm{B} 12 \sim \mathrm{B} 49$, indicating confined crystallization, whereas $T_{\mathrm{c}}{ }^{*}$ is $\mathrm{ca} .115^{\circ} \mathrm{C}$ $\left(\sim T_{\mathrm{g}}\right)$ for B61 $\sim \mathrm{B} 79$, suggesting complicated crystallization 

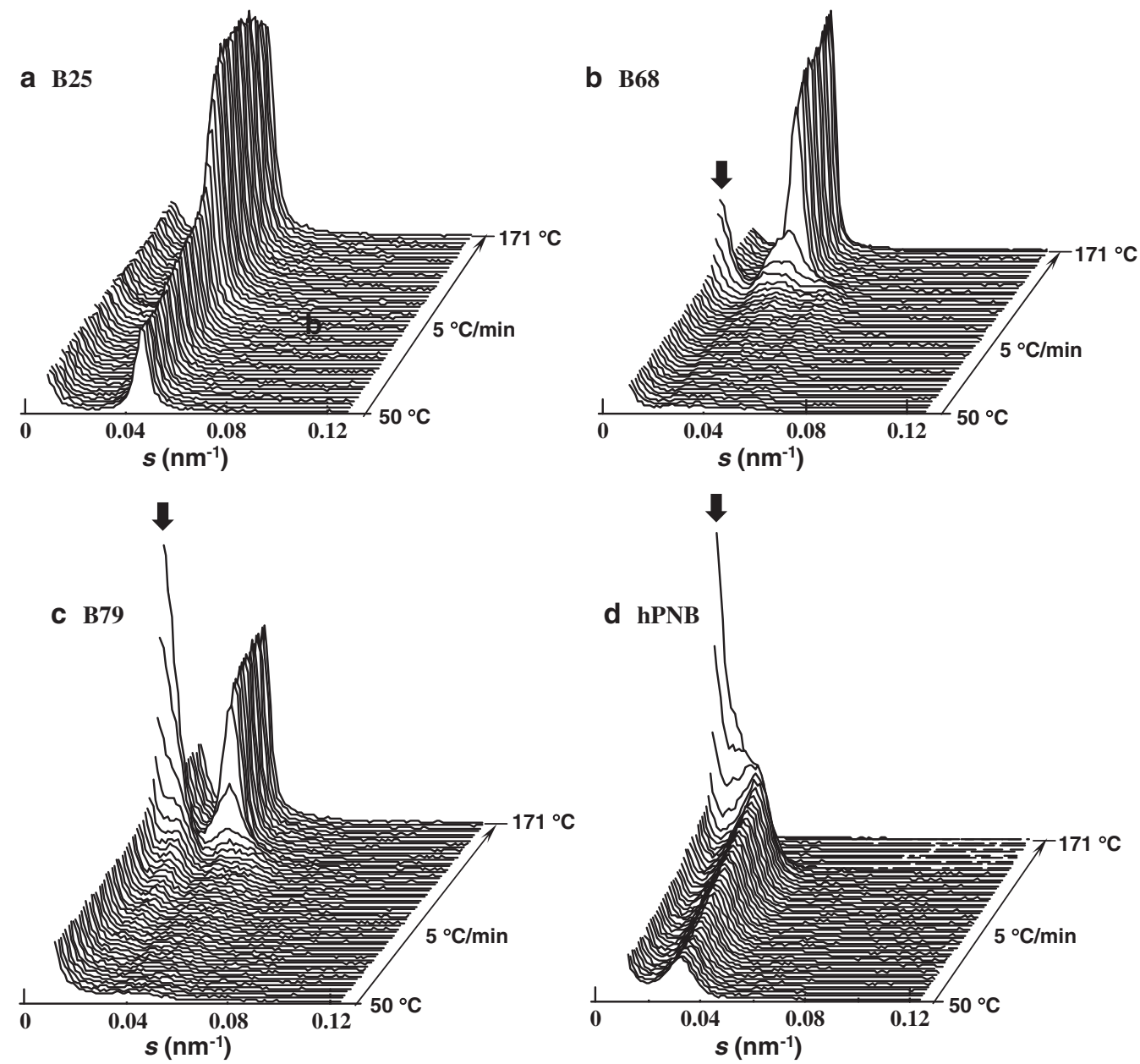

Figure 3. Time-resolved SR-SAXS curves during heating from $50^{\circ} \mathrm{C}$ to $171^{\circ} \mathrm{C}$ at $5^{\circ} \mathrm{C} / \mathrm{min}$ for $\mathrm{B} 25$ (a), B68 (b), B79 (c), and $\mathrm{hPNB}$ (d), which were in advance cooled from $150^{\circ} \mathrm{C}$ into room temperature at $-5^{\circ} \mathrm{C} / \mathrm{min}$.

which will depend on the crystallization condition. This fact is strongly supported by the DSC results showing that the crystallinity of hPNB blocks for B61 B79 is significantly larger than that for B12 B49. ${ }^{9,25,27}$ In summary, Figure 2 indicates that $\mathrm{B} 12 \sim \mathrm{B} 49$ have $T_{\mathrm{g}} \gg T_{\mathrm{c}}{ }^{*}$ to result in confined crystallization, whereas $\mathrm{B} 61 \sim \mathrm{B} 79$ have $T_{\mathrm{c}}{ }^{*} \sim T_{\mathrm{g}}$, and the crystallization of hPNB blocks at $T_{\mathrm{c}}{ }^{*}$ will be considerably influenced by $T_{\mathrm{g}}$ of hPMTF blocks. This means that the resulting morphology and eventually the melting behavior depend significantly on the crystallization condition such as the crystallization time $t_{\mathrm{c}}$ at $T_{\mathrm{c}}{ }^{*}$.

\section{SR-SAXS Curves during Heating}

Figure 3 shows the typical time-resolved SR-SAXS curves during heating from $50{ }^{\circ} \mathrm{C}$ to $171{ }^{\circ} \mathrm{C}$ at $5{ }^{\circ} \mathrm{C} / \mathrm{min}$ for $\mathrm{B} 25$ (a), B68 (b), B79 (c), and hPNB (d), which were in advance cooled down from $150^{\circ} \mathrm{C}$ into room temperature at $-5^{\circ} \mathrm{C} / \mathrm{min}$ (Figure 1a). The peak intensity appearing at $50^{\circ} \mathrm{C}$ for $\mathrm{B} 25$ increases drastically in the melting temperature range of hPNB blocks (Figure 3a), but the angular position of the intensity peak does not change through the heating process and is virtually identical to that of the molten microdomain structure.

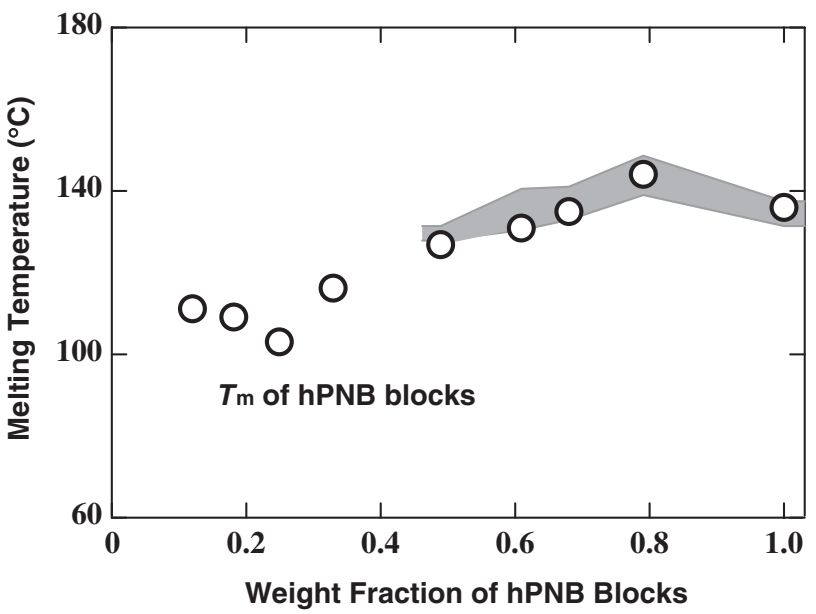

Figure 4. $T_{\mathrm{m}}$ obtained from DSC measurements at a heating rate of $5^{\circ} \mathrm{C} /$ min plotted against the weight fraction of hPNB blocks in the system. The gray area represents the temperature range where the excess upturn SAXS is observed when the sample is heated at $5{ }^{\circ} \mathrm{C} / \mathrm{min}$. 
Figure 3a clearly indicates that B25 (and also B12, B18, and B33) forms the crystallized microdomain structure at $50{ }^{\circ} \mathrm{C}$, and any morphological transition does not occur in the melting range of hPNB blocks. The increase in the peak intensity simply arises from the change of electron density contrast in hPNB microdomains by melting.

The SR-SAXS curves of B68 and B79 shown in Figures 3b and $3 \mathrm{c}$ seem to have no distinct scattering peaks at low temperatures $\left(50^{\circ} \mathrm{C} \leq T \leq 120^{\circ} \mathrm{C}\right)$, but they actually have the scattering peaks mainly arising from the crystallized lamellar morphology, which can be easily found in a logarithmic plot of the scattered intensity against $s$ (Figure 6). The small difference in electron density between the crystallized hPNB and amorphous hPMTF domains will be responsible for the small peak intensity. ${ }^{38}$ The SR-SAXS curves at higher temperatures $\left(>120^{\circ} \mathrm{C}\right.$ ) have the pronounced scattering peak arising from the molten microdomain structure. In addition to the scattered peak at the finite angle, Figure $3 b$ and $3 c$ show a transient excess scattering at low angles (indicated by an arrow in Figure $3 \mathrm{~b}$ and $3 \mathrm{c}$ ). This upturn scattering appears only at the temperature range where the main peak intensity increases drastically, which will be caused by the melting of hPNB blocks, as described in the heating process of B25. This excess scattering can be also clearly observed during the melting process of hPNB homopolymers (Figure 3d).

In order to understand the relation between the hPNB melting and the emergence of excess scattering, Figure 4 shows $T_{\mathrm{m}}$ (circle) and the temperature range of excess scattering (gray area) plotted against $\phi_{\mathrm{hPNB}}$, where $T_{\mathrm{m}}$ is completely included in the gray area. Therefore, we can conclude that the transient excess scattering observed at low angles is intimately related to the melting of hPNB blocks during heating.

The excess scattering intensity depends significantly on $\phi_{\mathrm{hPNB}}$, as observed in Figure $3 \mathrm{~b}$ and $3 \mathrm{c}$. Figure 5 shows the $\phi_{\mathrm{hPNB}}$ dependence of the normalized maximum intensity $I_{\mathrm{N}}$ of the excess scattering for hPNB- $b$-hPMTF with the thermal history shown in Figure 1a, where $I_{\mathrm{N}}$ is defined as,

$$
I_{N}=\frac{\text { maximum intensity at } s=0.02 \mathrm{~nm}^{-1} \text { during heating }}{\text { scattered intensity at } s=0.02 \mathrm{~nm}^{-1} \text { in the melt }\left(\sim 150^{\circ} \mathrm{C}\right)}
$$

$I_{\mathrm{N}}$ is almost 1 for $\mathrm{B} 12 \sim \mathrm{B} 33$, indicating no excess scattering appears in the melting range of hPNB blocks. On the other hand, $I_{\mathrm{N}}$ increases considerably with increasing $\phi_{\mathrm{hPNB}}$ for $\mathrm{B} 61 \sim \mathrm{B} 79$, and will take a large value at $\phi_{\mathrm{hPNB}} \rightarrow 1$. In summary, the excess upturn scattering observed at low angles during heating is intimately related to the melting of hPNB blocks and also depends significantly on $\phi_{\mathrm{hPNB}}$.

\section{Morphology Formed by hPNB Crystallization at $\boldsymbol{T}_{\mathrm{c}}{ }^{*}$}

In order to clarify the origin of the excess scattering at low angles, we observed the melting behavior of hPNB- $b$-hPMTF with the thermal history shown in Figure 1b. First, we investigated the time evolution of the morphology formed by the crystallization of hPNB blocks at $T_{\mathrm{c}}{ }^{*}$ using a static SAXS

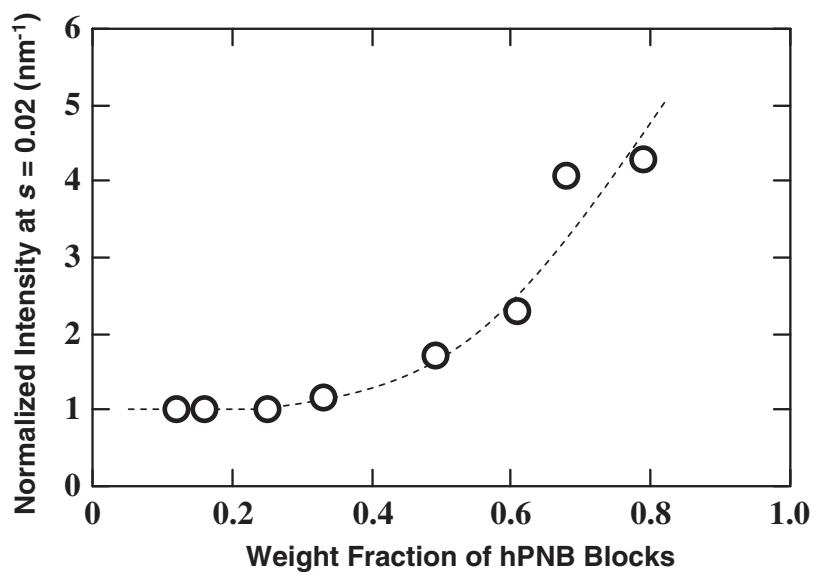

Figure 5. Normalized maximum intensity of the excess scattering at $s=$ $0.02 \mathrm{~nm}^{-1} / l_{\mathrm{N}}$, i.e., the maximum intensity at $s=0.02 \mathrm{~nm}^{-1}$ during heating divided by the melt intensity $\left(\sim 150^{\circ} \mathrm{C}\right)$ at $s=0.02 \mathrm{~nm}^{-1}$ plotted against the weight fraction of hPNB blocks in the system for hPNB-b-hPMTF with the thermal history shown in Figure 1a.
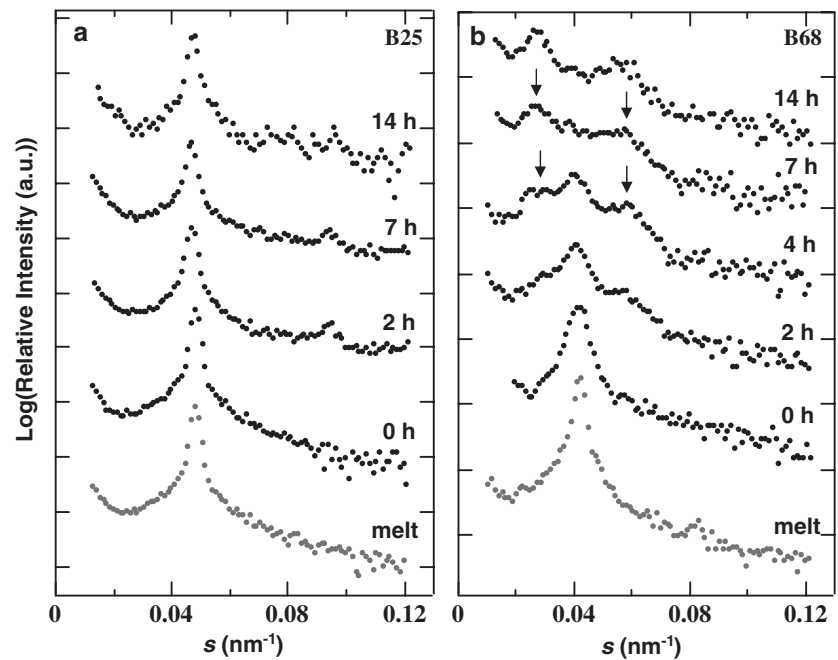

Figure 6. Static SAXS curves at room temperature for B25 (a) and B68 (b) crystallized at $T_{\mathrm{c}}{ }^{*}$ for each $t_{\mathrm{c}}$ indicated. The gray data (bottom) represent the SAXS curve from the molten microdomain structure at $150^{\circ} \mathrm{C}$. The SAXS curves from the crystallized samples are shifted upward successively for legibility.

method for selected hPNB- $b$-hPMTF copolymers. The typical SAXS curves for B25 and B68 are shown in Figure 6 as a function of $t_{\mathrm{c}}$. Figure 6 also includes the SAXS curve from the molten microdomain structure at $150^{\circ} \mathrm{C}$ (gray curves). The SAXS curve for B25 (Figure 6a) does not change practically with increasing $t_{\mathrm{c}}$ and resembles that for the molten B25. The SAXS curve for B68 (Figure 6b), on the other hand, changes significantly with $t_{\mathrm{c}}$; it has a scattering peak when $t_{\mathrm{c}}=0 \mathrm{~h}$, however, another scattering peaks (indicated by arrows in Figure 6b) appear with increasing $t_{\mathrm{c}}$, by which the original SAXS peak is completely replaced at $t_{\mathrm{c}}=7$ and $14 \mathrm{~h}$. The angular positions of new peaks exactly correspond to a ratio of $1: 2$, suggesting that the crystallized lamellar morphology is slowly and steadily formed in the system with increasing $t_{\mathrm{c}}$ at the expense of the molten microdomain structure. Therefore, 


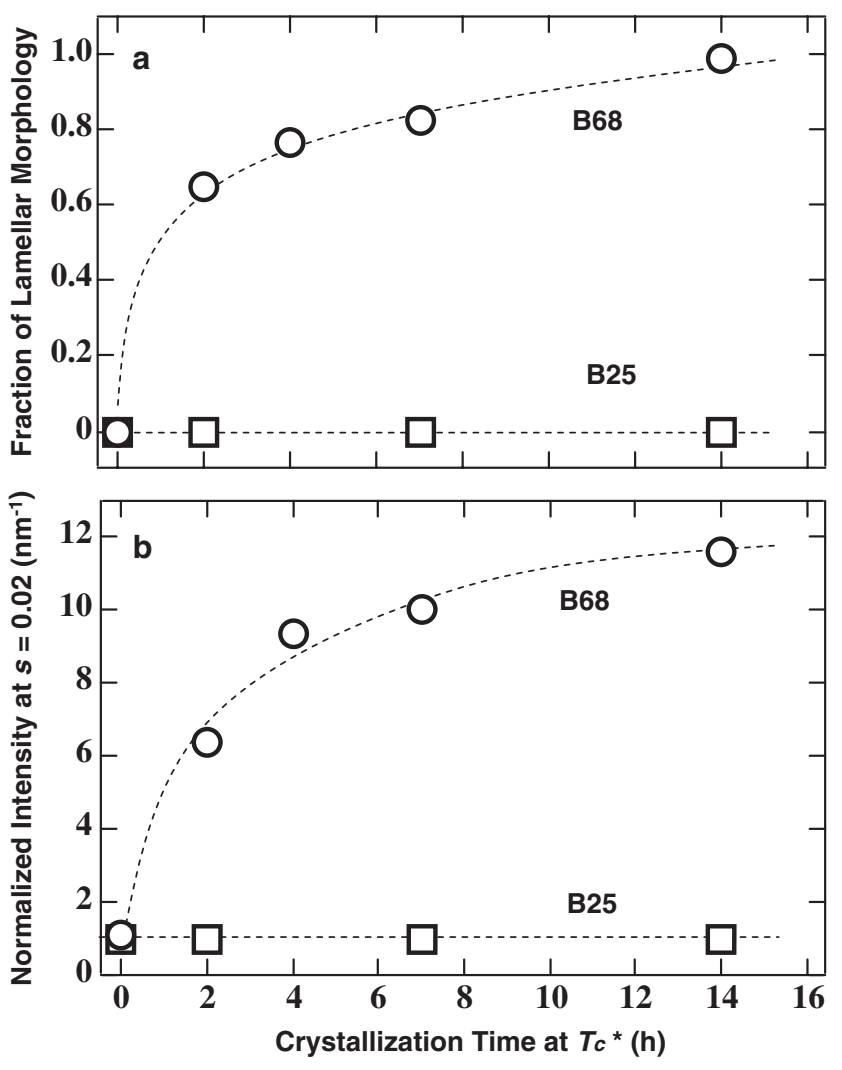

Figure 7. (a) The volume fraction of the crystallized lamellar morphology formed in the system plotted against crystallization time for B25 (square) and B68 (circle). (b) Normalized maximum intensity of the excess scattering at $s=0.02 \mathrm{~nm}^{-1}$ plotted against crystallization time for B25 (square) and B68 (circle).

B68 crystallized at $T_{\mathrm{c}}{ }^{*}$ for an insufficient time (i.e., B68 isothermally crystallized at $T_{\mathrm{c}}{ }^{*}$ for $t_{\mathrm{c}} \leq 4 \mathrm{~h}$ and B68 with the thermal history shown in Figure 1a) is expected to have a mosaic structure at room temperature consisting of the crystallized lamellar morphology and the crystallized microdomain structure.

It is possible to evaluate the volume fraction of the crystallized lamellar morphology $\phi_{\mathrm{L}}$ formed in the system as a function of $t_{\mathrm{c}}$ assuming that the SAXS curve at $0 \mathrm{~h}$ arises only from the crystallized microdomain structure and that at $14 \mathrm{~h}$ from the crystallized lamellar morphology. Figure $7 \mathrm{a}$ shows the plot of $\phi_{\mathrm{L}}$ against $t_{\mathrm{c}}$ for B25 (square) and B68 (circle). $\phi_{\mathrm{L}}$ is 0 for B25 irrespective of $t_{c}$, indicating again that the hPNB block crystallizes completely within the microdomain structure (confined crystallization) because $T_{\mathrm{g}}$ of hPMTF blocks is significantly higher than $T_{\mathrm{c}}{ }^{*}$ of hPNB blocks (Figure 2). $\phi_{\mathrm{L}}$ for $\mathrm{B} 68$, on the other hand, increases gradually with increasing $t_{\mathrm{c}}$. The crystalline hPNB block is the major component in B68 and the driving force of crystallization is large even at temperatures close to $T_{\mathrm{g}}$, resulting in the crystallized lamellar morphology. Figure 7a implies that the crystallization rate of hPNB blocks in B68 is considerably decelerated owing to the effect of glass transition, and the formation of the crystallized lamellar morphology at $T_{\mathrm{c}}{ }^{*}$ needs a long time $(\sim 10-14 \mathrm{~h})$ compared

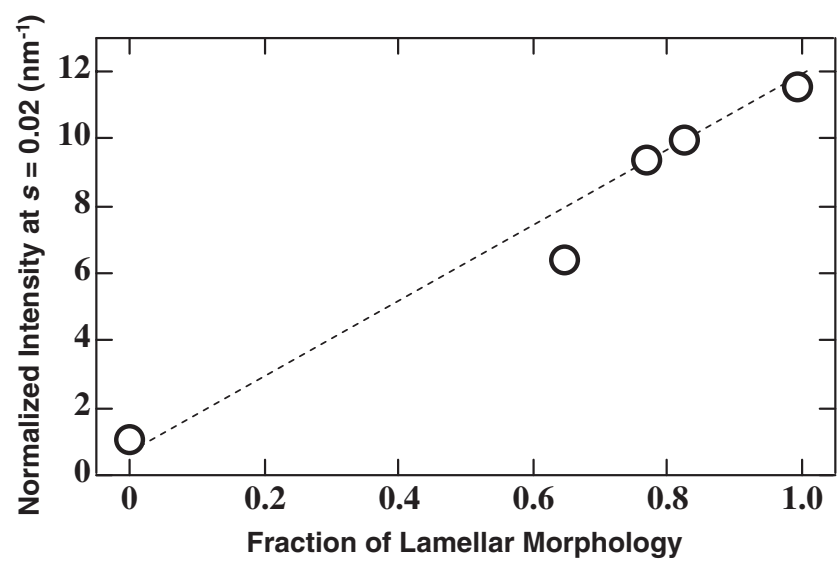

Figure 8. Normalized maximum intensity of the excess scattering at $s=$ $0.02 \mathrm{~nm}^{-1}$ plotted against volume fraction of lamellar morphology for B68.

to the low molecular weight crystalline-amorphous diblocks with $T_{\mathrm{c}} \gg T_{\mathrm{g}} \cdot{ }^{15-17}$

When the thermal history shown in Figure $1 \mathrm{~b}$ is applied to hPNB- $b$-hPMTF, the SR-SAXS curves, in particular the excess scattering intensity, during heating changed significantly with increasing crystallization time $t_{\mathrm{c}}$ at $T_{\mathrm{c}}{ }^{*}$ (data not shown). Figure 7b shows the $t_{\mathrm{c}}$ dependence of $I_{\mathrm{N}}$ for B25 and B68, where $I_{\mathrm{N}}$ for B25 is 1 irrespective of $t_{\mathrm{c}}$, but $I_{\mathrm{N}}$ for B68 increases moderately with increasing $t_{\mathrm{c}}$. In order to find the quantitative relationship between $I_{\mathrm{N}}$ and the amount of the crystallized lamellar morphology, we plot $I_{\mathrm{N}}$ (Figure 7b) against $\phi_{\mathrm{L}}$ (Figure 7a) in Figure 8, where we can find a linear relation between them. That is, $I_{\mathrm{N}}$ is proportional to the volume fraction of the crystallized lamellar morphology existing in the system before heating. In summary, the transient excess scattering observed at low angles originates from the crystallized lamellar morphology, which has been formed in advance by the crystallization of the hPNB block at $T_{\mathrm{c}}{ }^{*}$.

\section{DISCUSSION}

The pronounced upturn X-ray scattering at low angles is sometimes reported during the melting process of crystalline homopolymers. ${ }^{29-31}$ Wang et al., for example, investigated the melting behavior of $s y n$-polypropylene $\left(s \mathrm{PP}, M_{\mathrm{w}} \sim 174,000\right)$ using time-resolved SR-SAXS, ${ }^{31}$ and found a significant upturn scattering in the melting temperature range of $s \mathrm{PP}$. They concluded that this excess scattering originated from the transient heterogeneous structure appearing during the melting of $s$ PP crystals. However, the substantial origin of this scattering is not clear, because it is difficult to characterize the heterogeneous structure only from the excess scattering. In the present study, we observed the excess scattering during the melting process of hPNB homopolymers (Figure 6d). In addition, similar melting behavior was observed for $\operatorname{poly}(\varepsilon$ caprolactone) (PCL) homopolymers $\left(M_{\mathrm{n}} \sim 11,000\right)$ and poly(ethylene oxide) (PEO) homopolymers $\left(M_{\mathrm{n}} \sim 15,000\right)$ in our preliminary studies. 
On the contrary, we could not observe such pronounced excess upturn scattering when we pursued the melting behavior of PCL-block-polybutadiene (PCL- $b$-PB) ${ }^{34}$ and polyethyleneblock-PCL (PE- $b$-PCL) ${ }^{39}$ using SR-SAXS. In these copolymers, the glass transition temperature of amorphous blocks (PB blocks for PCL- $b$-PB and PCL blocks for PE- $b$-PCL) is extremely lower than the melting temperature of crystalline blocks, so that the melting of crystalline blocks immediately leads to the morphological transition (crystallized lamellar morphology $\rightarrow$ molten microdomain structure) without any intermediate structure, ${ }^{15}$ which is substantially different from the present hPNB- $b$-hPMTF with $T_{\mathrm{g}} \sim T_{\mathrm{m}}$. This fact may imply that the emergence of excess scattering is related to the stability (or relaxation time) of some heterogeneous structure transiently appearing during melting.

The electron density difference between the crystallized hPNB and the amorphous hPMTF is expected to be extremely small, as found from the small SR-SAXS peak (Figures $3 \mathrm{~b}$ and $3 c)$. Therefore, the excess scattering arises from the electron density contrast between amorphous hPMTF/amorphous hPNB or amorphous hPNB/amorphous hPNB just melted during heating. The fact that the excess scattering is observed for crystalline homopolymers ( $s$ PP, hPNB, PCL, and PEO), where no second component exists in the system, suggests that the excess scattering arises from the electron density contrast between the melting hPNB regions and the amorphous hPNB regions originally existing in the crystallized lamellar morphology. That is, the amorphous hPNB regions just melted might have a slightly higher density compared to the originally amorphous hPNB regions, and the relaxation process of higher density regions into normal density regions takes a substantial time because of slow mobility owing to $T_{\mathrm{m}} \sim T_{\mathrm{g}}$. Therefore, we can observe the transient scattering only for crystallineamorphous diblocks with $T_{\mathrm{m}}$ (or $\left.T_{\mathrm{c}}{ }^{*}\right) \sim T_{\mathrm{g}}$. However, we have no chance to observe the density heterogeneity during the melting of diblocks with $T_{\mathrm{m}} \gg T_{\mathrm{g}}$, because the amorphous region just melted transforms immediately into the part of microdomain structures and eventually no third phase (i.e., microdomain structure with higher density domains) is observed during melting. ${ }^{15}$ In the melting process of crystalline homopolymers, the density heterogeneity will relax gradually according to the thermal fluctuation because no structure is formed after melting. Therefore, we have a finite period to have the density heterogeneity, during which we can observe the excess X-ray scattering. This speculation is not supported by any experimental results, and it is necessary to quantitatively investigate the heterogeneous structure appearing during the melting of our block copolymers.

\section{CONCLUSION}

We have investigated the melting behavior of a series of new crystalline-amorphous diblock copolymers, hydrogenated polynorbornene-block-hydrogenated poly(1,4-methano1,4,4a,9a-tetrahydrofluorene) (hPNB- $b$-hPMTF), using timeresolved SR-SAXS methods. The crystallization temperature of
hPNB blocks at the maximum rate $T_{\mathrm{c}}{ }^{*}$ was nearly the same to the glass transition temperature of hPMTF blocks for hPNBrich hPNB- $b$-hPMTF copolymers. The excess upturn X-ray scattering at low angles was transiently observed in the melting temperature range of hPNB blocks during heating, which depended significantly on the composition and the crystallization time at $T_{\mathrm{c}}{ }^{*}$. The crystallized lamellar morphology was responsible for the emergence of this scattering, because the excess scattering intensity was proportional to the volume fraction of the crystallized lamellar morphology existing in the system before heating. One of the possible scenarios is that such excess scattering arises from the heterogeneous structure consisting of just melted hPNB regions (with slightly higher density) and originally amorphous hPNB regions (with normal density) within the crystallized lamellar morphology.

Acknowledgment. This work was supported in part by NEDO (New Energy and Industrial Technology Development Organization) launched in 2001. The SR-SAXS measurement has been performed under the approval of Photon Factory Advisory Committee (No. 2008G031).

Received: June 12, 2009

Accepted: August 9, 2009

Published: September 28, 2009

\section{REFERENCES}

1. "Developments in Block Copolymer Science and Technology," I. W. Hamley, Ed., Wiley, New York, 2004.

2. A. J. Müller, V. Balsamo, and M. L. Arnal, Adv. Polym. Sci., 190, 1 (2005).

3. B. Nandan, J. Y. Hsu, and H. L. Chen, J. Macromol. Sci., Part C: Polym. Rev., 46, 143 (2006).

4. I. W. Hamley, J. P. A. Fairclough, N. J. Terrill, A. J. Ryan, P. M. Lipic, F. S. Bates, and E. T. Andrews, Macromolecules, 29, 8835 (1996).

5. S. Nojima, H. Tanaka, A. Rohadi, and S. Sasaki, Polymer, 39, 1727 (1998).

6. P. A. Weimann, D. A. Hajduk, C. Chu, K. A. Chaffin, J. C. Brodil, and F. S. Bates, J. Polym. Sci., Part B: Polym. Phys., 37, 2053 (1999).

7. Y. L. Loo, R. A. Register, and D. H. Adamson, Macromolecules, 33, 8361 (2000).

8. L. Zhu, B. H. Calhoun, Q. Ge, R. P. Quirk, S. Z. D. Cheng, E. L. Thomas, B. S. Hsiao, F. Yeh, L. Lin, and B. Lotz, Macromolecules, 34, 1244 (2001).

9. Y. L. Loo, R. A. Register, and A. J. Ryan, Macromolecules, 35, 2365 (2002).

10. L. Zhu, P. Huang, W. Y. Chen, Q. Ge, R. P. Quirk, S. Z. D. Cheng, E. L. Thomas, B. Lotz, B. S. Hsiao, F. Yeh, and L. Liu, Macromolecules, 35, 3553 (2002).

11. H. Takeshita, N. Ishii, C. Araki, M. Miya, K. Takenaka, and T. Shiomi, J. Polym. Sci., Part B: Polym. Phys., 42, 4199 (2004).

12. P. Huang, Y. Guo, R. P. Quirk, J. Ruan, B. Lotz, E. L. Thomas, B. S. Hsiao, C. A. Avila-Orta, I. Sics, and S. Z. D. Cheng, Polymer, 47, 5457 (2006).

13. A. T. Lorenzo, M. L. Arnal, A. J. Müller, A. B. Fierro, and V. Abetz, Eur. Polym. J., 42, 516 (2006).

14. Y. S. Sun, T. M. Chung, Y. J. Li, R. M. Ho, B. T. Ko, and U. S. Jeng, Macromolecules, 40, 6778 (2007).

15. S. Nojima, K. Kato, S. Yamamoto, and T. Ashida, Macromolecules, 25, 2237 (1992). 
16. S. Nojima, H. Nakano, Y. Takahashi, and T. Ashida, Polymer, 35, 3479 (1994).

17. P. Rangarajan, R. A. Register, L. J. Fetters, W. Bras, S. Naylor, and A. J. Ryan, Macromolecules, 28, 4932 (1995).

18. A. J. Ryan, I. W. Hamley, W. Bras, and F. S. Bates, Macromolecules, 28, 3860 (1995).

19. D. J. Quiram, R. A. Register, G. R. Marchand, and A. J. Ryan, Macromolecules, 30, 8338 (1997).

20. G. Floudas, B. Vazaiou, F. Schipper, R. Ulrich, U. Wiesner, H. Iatrou, and N. Hadjichristidis, Macromolecules, 34, 2947 (2001).

21. J. T. Xu, J. P. A. Fairclough, S. M. Mai, C. Chaibundit, M. Mingvanish, C. Booth, and A. J. Ryan, Polymer, 44, 6843 (2003).

22. Y. Y. Huang, C. H. Yang, H. L. Chen, F. C. Chiu, T. L. Lin, and W. Liou, Macromolecules, 37, 486 (2004).

23. J. Y. Hsu, I. F. Hsieh, B. Nandan, F. C. Chiu, J. H. Chen, U. S. Jeng, and H. L. Chen, Macromolecules, 40, 5014 (2007).

24. Y. Qian, T. Cai, and W. Hu, Macromolecules, 41, 7625 (2008).

25. L. Zhu, B. R. Mimnaugh, Q. Ge, R. P. Quirk, S. Z. D. Cheng, E. L. Thomas, B. Lotz, B. S. Hsiao, F. Yeh, and L. Liu, Polymer, 42, 9121 (2001).

26. R. M. Ho, F. H. Lin, C. C. Tsai, C. C. Lin, B. T. Ko, B. S. Hsiao, and I. Sics, Macromolecules, 37, 5985 (2004).

27. R. M. Ho, T. M. Chung, J. C. Tsai, J. C. Kuo, B. S. Hsiao, and I. Sics, Macromol. Rapid Commun., 26, 107 (2005).

28. In this study, we always chose $T_{\mathrm{c}}{ }^{*}$ as the crystallization temperature $T_{\mathrm{c}}$ for every hPNB-b-hPMTF. As a result, B61 $\sim$ B79 were satisfied with the condition of $T_{\mathrm{g}} \sim T_{\mathrm{c}}$, and others had $T_{\mathrm{g}}>T_{\mathrm{c}}$ (confined crystallization). See Table I.

29. B. S. Hsiao, K. H. Gardner, D. Q. Wu, and B. Chu, Polymer, 34, 3996
(1993).

30. K. N. Krueger and H. G. Zachmann, Macromolecules, 26, 5202 (1993).

31. Z. G. Wang, X. H. Wang, B. S. Hsiao, R. A. Phillips, F. J. MedellinRodriguez, S. Srinivas, H. Wang, and C. C. Han, J. Polym. Sci., Part B: Polym. Phys., 39, 2982 (2001).

32. No information is available in the literature on the nature of hPMTF homopolymers, so that the interaction between hPNB and hPMTF blocks can not be estimated. However, the sharp SAXS peak from the microdomain structure was observed up to $171^{\circ} \mathrm{C}$ (Figure 3), indicating that $T_{\mathrm{ODT}}$ is higher than $171^{\circ} \mathrm{C}$ for every hPNB-b-hPMTF.

33. S. Nojima, K. Hashizume, A. Rohadi, and S. Sasaki, Polymer, 38, 2711 (1997).

34. S. Nojima, N. Kikuchi, A. Rohadi, S. Tanimoto, and S. Sasaki, Macromolecules, 32, 3727 (1999).

35. H. Ikeda, Y. Ohguma, and S. Nojima, Polym. J., 40, 241 (2008).

36. T. Sakurai, Y. Ohguma, and S. Nojima, Polym. J., 40, 971 (2008).

37. The melting peak of hPNB blocks is unimodal in every hPNB- $b$ hPMTF, suggesting that the melting and re-crystallization of immature crystals do not occur during heating.

38. The crystallinity of hPNB blocks in B68 and B79 is significantly higher than that in B25, as described in 3-1. This result leads to the smaller scattering intensity from the crystallized lamellar morphology, because the electron density of crystallized hPNB, rather than that of amorphous hPNB blocks, is closer to PMTF blocks.

39. S. Nojima, T. Kiji, and Y. Ohguma, Macromolecules, 40, 7566 (2007). When the PE block is melting in PE- $b$-PCL, the PCL block acts as an amorphous block because $T_{\mathrm{m}, \mathrm{PE}} \gg T_{\mathrm{m}, \mathrm{PCL}}$. 